\title{
Editorial
}

\section{Proceedings of XXXII GIRI meeting}

\section{Carolina Camargo de Oliveira}

\author{
Associate Professor - Cell Biology Department - Biological Section - Universidade Federal do \\ Paraná, Curitiba (Brazil)
}

Annually, clinical practitioners and researchers from different areas joint efforts to discuss relevant findings related to high dilutions at the International Research Group on Very Low Dose and High Dilution Effects (GIRI) meeting. This year the meeting was organized jointly with the National Association for Traditional and Complementary Medicine of Russia, and held in Moscow on the 28-29 June. Topics included physicochemical and mathematical models to identify high dilutions in solutions, biological models using in vitro and in vivo studies to determine its effects, as well as clinical observations. These were two days of presentations that ended in a round of discussion about how to improve and join forces to translate clinical observations to basic research findings and vice versa.

High standards scientific methods,-reproducibility, and fransdisciplinarity are key points of any quality research. It was possible-to recognize that despite of several difficulties, anyone struggling to study high dilutions is engaged to all these points. It was also noticeable a growing network of people focused on unravel ts athways that ullimate culminate in successful patient's wellbeing. Hopefully everyone committed to overcome all imposed barriers will find ways of continuing to perform quality research, upgrading basic knowledge towards better understanding of high dilutions actions. Thus acting together, we hope that this model will gain strengths and will perpetuate the memory of Dr. Peter Fisher; someone who was an example to be followed, a keen researcher that truly worked in favor of patient's holistic treatment.

(C) International Journal of High Dilution Research. Not for commercial purposes. 